\title{
Testing Metadata Existence of Web Map Services
}

\author{
Jan Růžička \\ Institute of Geoinformatics \\ VSB - TU of Ostrava \\ jan.ruzicka vsb.cz
}

Keywords: Web Map Service, Metadata, Intelligent Map Systems

\begin{abstract}
For a general user is quite common to use data sources available on WWW. Almost all GIS software allow to use data sources available via Web Map Service (ISO/OGC standard) interface. The opportunity to use different sources and combine them brings a lot of problems that were discussed many times on conferences or journal papers. One of the problem is based on non existence of metadata for published sources. The question was: were the discussions effective? The article is partly based on comparison of situation for metadata between years 2007 and 2010. Second part of the article is focused only on 2010 year situation. The paper is created in a context of research of intelligent map systems, that can be used for an automatic or a semi-automatic map creation or a map evaluation.
\end{abstract}

\section{Intelligent map systems}

Intelligent systems, that can help to user with map composition should be based on knowledge base. Rules defined in the knowledge base can help with map creation to make it better and correct in a way of defined conditions. The project „The Intelligent System for Interactive Support of Thematic Map Design" should be focused on rules definition and pilot system creation for using this rules in a process of a map creation. What is necessary to make such system operable are sufficient data inputs. The inputs could be provided by user, when it is necessary. When it is possible the inputs should be available without user's activity. In many cases are metadata important input for map creation. This article is focused on metadata available for Web Map Services, that can be used for automatic or semi-automatic map creation based on expert system evaluation. 


\section{Web Map Service and metadata}

Metadata can help with correct data usage. Web Map Service described for example in [1] is a standardised definition of service interface that defines how to requests service to obtain digital map. The interface definition is quite simple and widely supported. That makes WMS good servant. What is very important is that a user can simply combine several WMS sources with general software. That makes WMS very bad master. A typical incorrect usage of WMS is described at the figure 1. The user combines two WMS sources. The first source publishes undermined areas. The second source publishes cadastral map. Both sources are created with different methods that leads into very different positional accuracy. While the cadastral map has maximal error in horizontal position less than 2 meters, the undermined areas can have maximal error in horizontal position more than 50 meters. The possible positional error is described at the figure. A user that does not know this metadata of used sources can make possible wrong decision (for example decide that parcel owned by Franta Novák is undermined).

\section{Uncertainty in undermined area impact on parcel of Franta Novák Gisov nad Ostravou, October 2004}

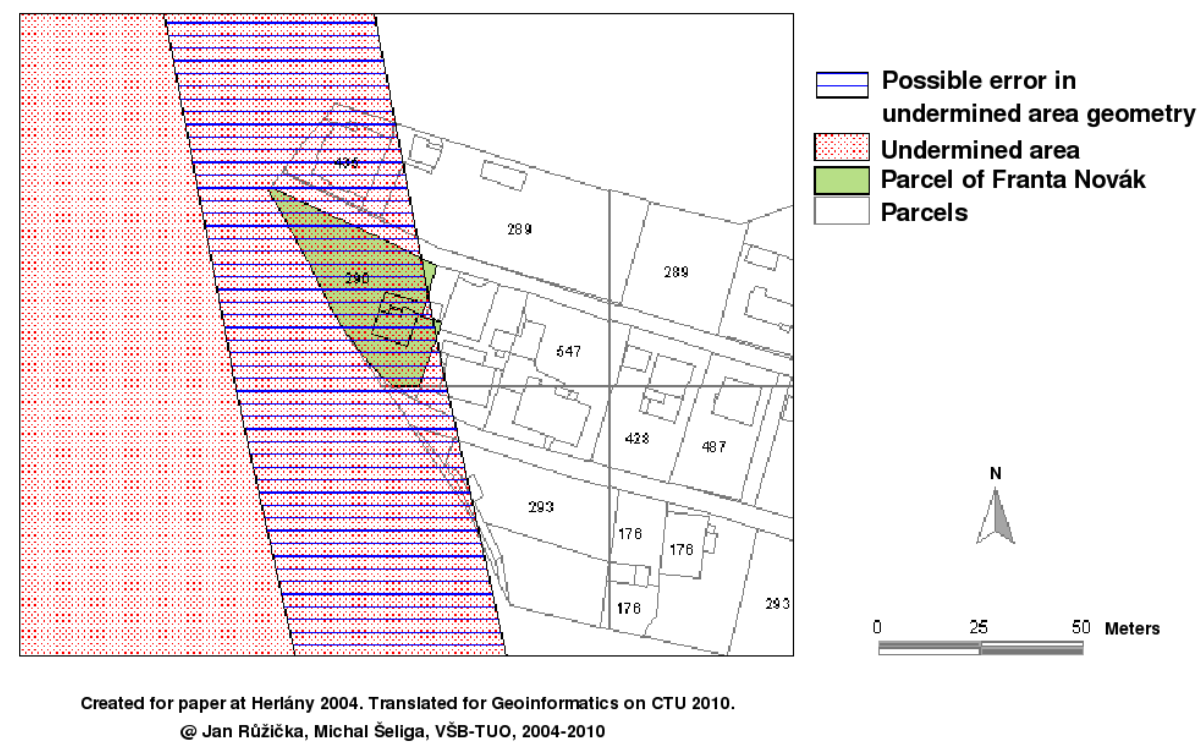

Figure 1: A possible wrong usage of WMS sources

The idea of automatic or semi-automatic map creation is quite old and for example described in [2]. Specification WMS contains metadata elements that can help with automatic or semiautomatic map creation. Basic metadata elements are available in Capabilities document, that is obtained according to GetCapabilities request on a service. The metadata are either fully contained in the document (e.q. Title, Contact, Abstract) or referenced to the external document (Layer metadata), so from that point of view is everything prepared for automatic or semi-automatic map creation. Our question was: How look the metadata in reality? 


\section{Tests of Czech WMS}

\section{7 year}

Roman Kazsper did in 2007 year tests of WMS for Czech republic that were publicly available. The results are in detail described in [3]. Here follows only a summary of the results.

At that time were tested about 30 services from the following providers:

- Regional Authority of the South Moravia Region

- Regional Authority of the Pardubice Region

- Regional Authority of the Hradec Králové Region

- Regional Authority of the Liberec Region

- Czech Environmental Information Agency

- Forest Management Institute

- T.G. Masaryk Water Research Institute

Some of the services missed keywords and contact information, all services except one provider missed metadata for used geodata. Roman Kaszper contacted all providers with request to correct their metadata. Some of them promised to correct the metadata, most of them did not even answer.

\section{0 year}

The services tested in 2007 year were tested in 2010 year to compare results. One provider improve metadata with contact information. One provider moved metadata for layers to a different location than is referenced from Capabilities document. So we must said that the situation is probably worse than 5 years ago.

\section{Test of World WMS in 2010 year}

If the situation in the Czech republic is so bad, how looks the situation in the whole world. For the test were identified 559 WMS services mainly from USA and Europe. Situation is described at the following figures.

\section{Conclusion}

Situation in the Czech Republic is similar to the global World situation, metadata for layers are not common even in Germany. Contacting providers and presentation of the results on conferences was not very successful, but we should keep to inform providers about their mistakes. For this purpose, according to tests in 2010 year was prepared a web service available via a web browser for testing WMS services. This service is described below. Finally we have 


\section{Completeness of metadata elements for WMS services} World

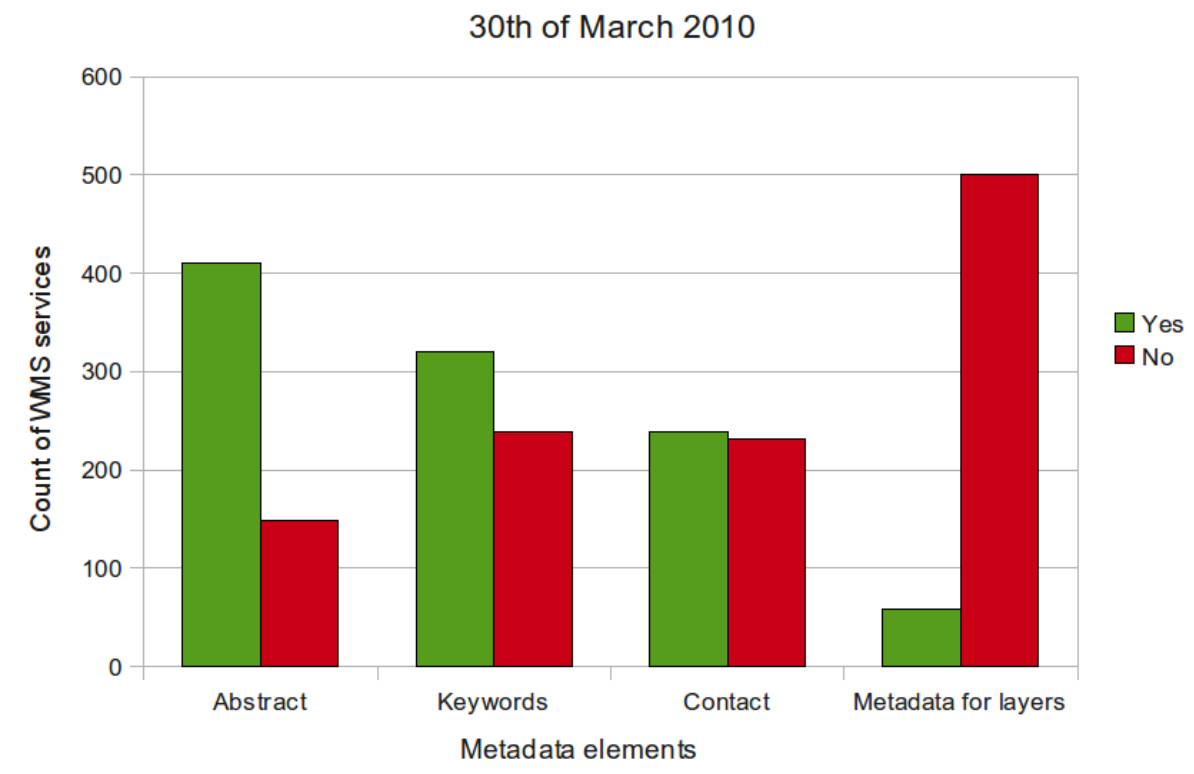

Figure 2: Completeness of metadata elements in all tested WMS (World)

\section{Completeness of metadata elements for WMS services Czech Republic}

30th of March 2010

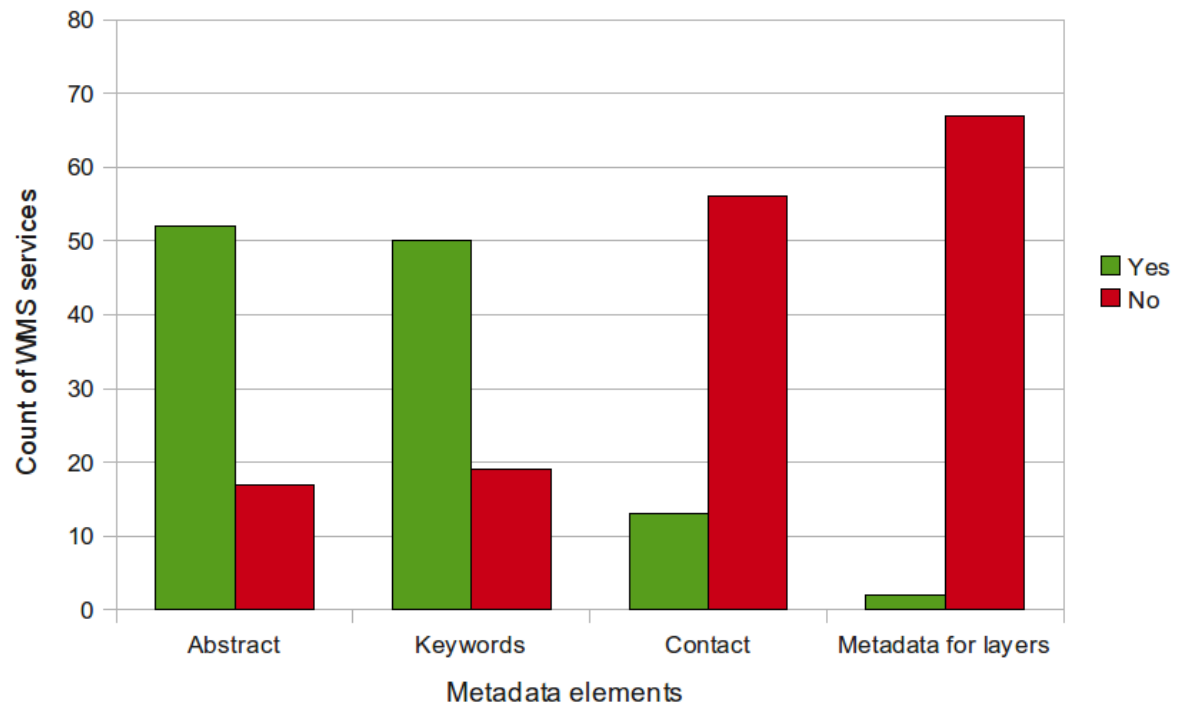

Figure 3: Completeness of metadata elements in WMS from the Czech republic

to find ways how to work without metadata correctly. One possible option is briefly described below. 


\section{Completeness of metadata elements for WMS services}

Canada

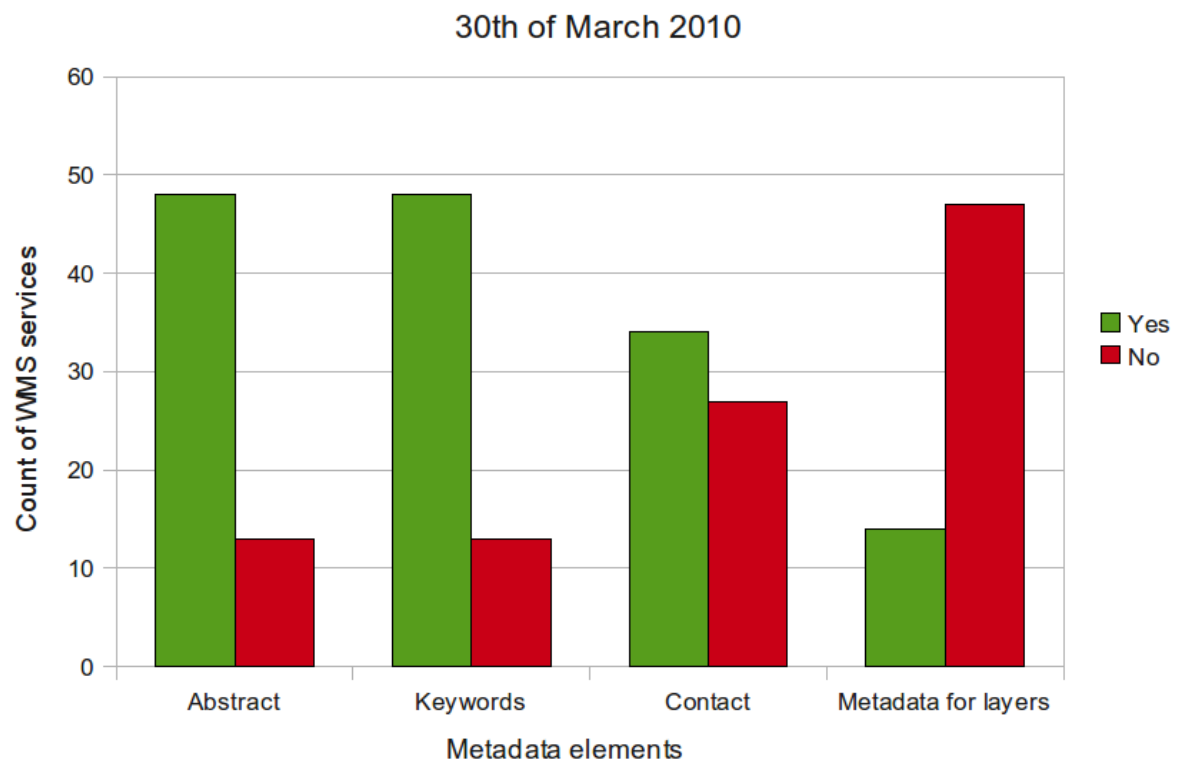

Figure 4: Completeness of metadata elements in WMS from Canada

\section{Completeness of metadata elements for WMS services USA}

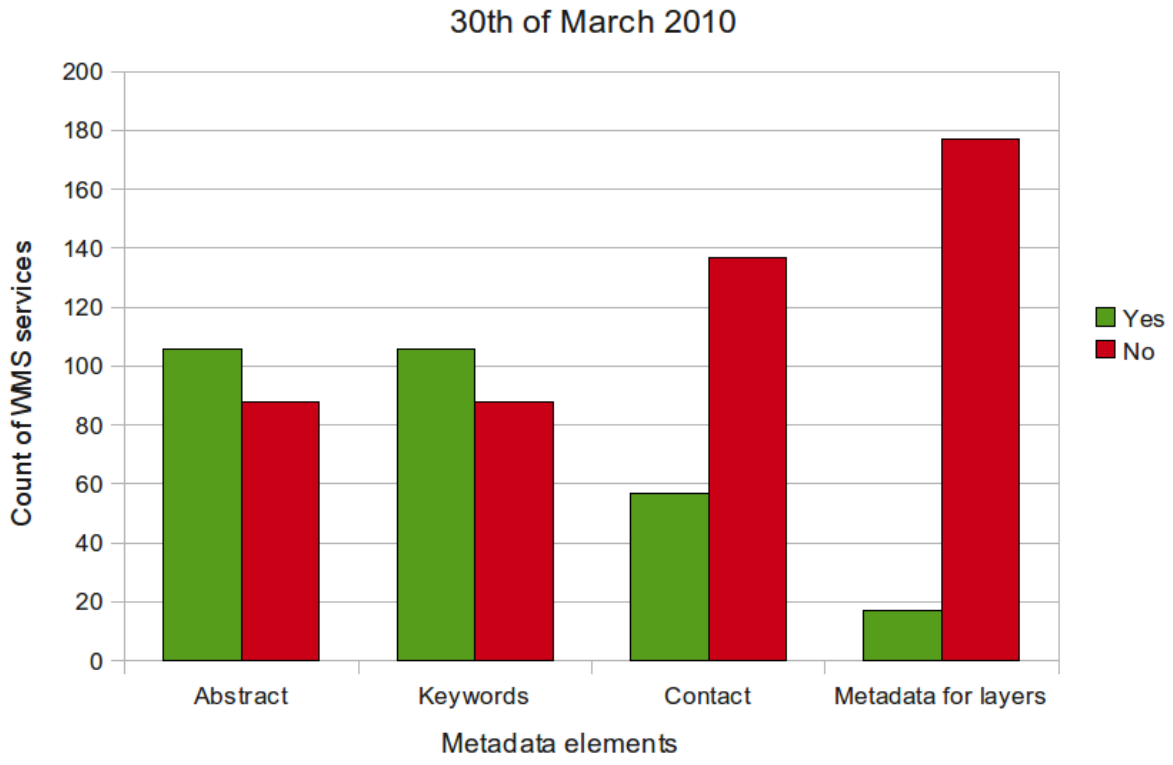

Figure 5: Completeness of metadata elements in WMS from the USA

\section{OGC Test Service}

This service can help with testing web services based on OGC Specifications. At the moment is 


\section{Completeness of metadata elements for WMS services Germany}

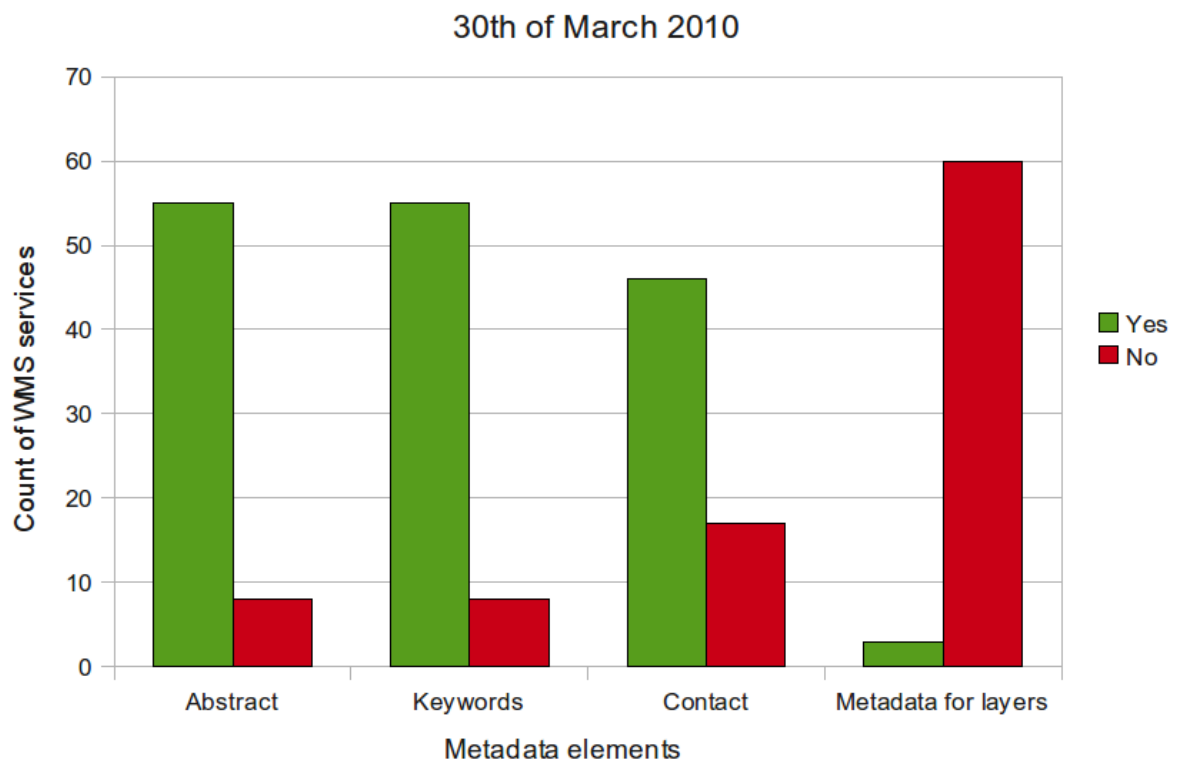

Figure 6: Completeness of metadata elements in WMS from Germany

\section{Completeness of metadata elements for WMS services Italy}

30th of March 2010

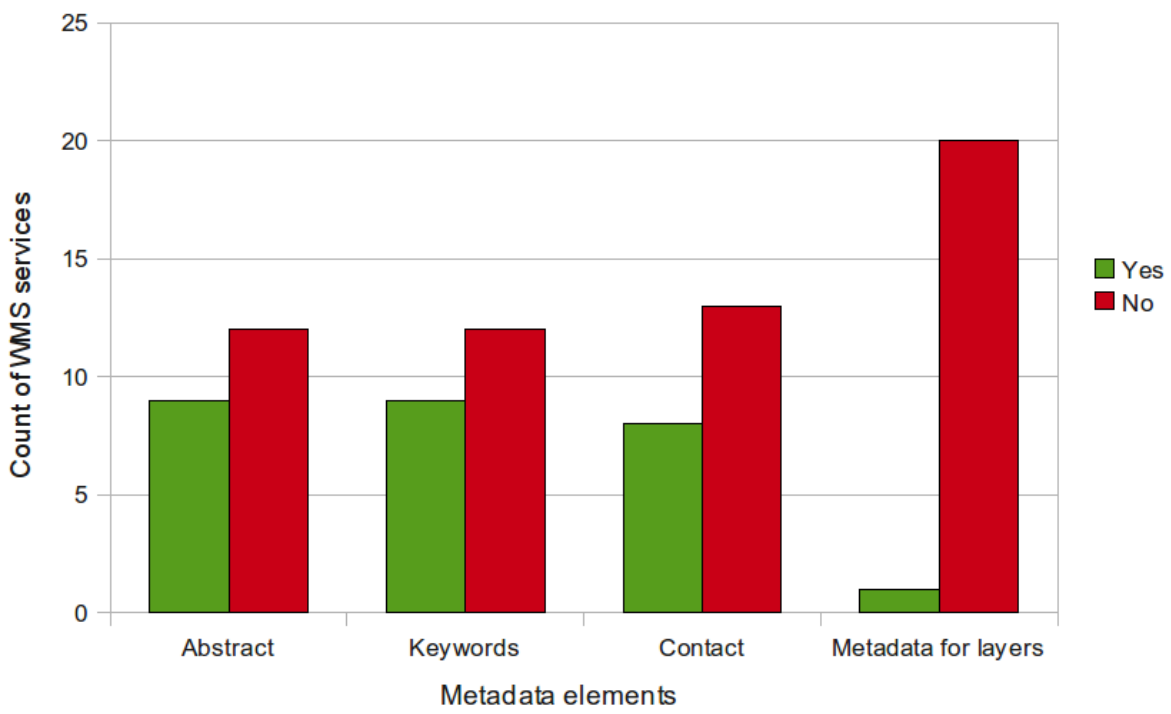

Figure 7: Completeness of metadata elements in WMS from Italy

functional only first service that validates WMS Capabilities document according to metadata content. The service is based on similar principle as W3C HTML or CSS Validator service. A user can specify URL of the service in a simple form (fig. 8). The service is requested 
with GetCapabilities request and the response is validated according to existence of metadata elements. If the Capabilities response does not contain sufficient metadata the user is informed by error message (fig. 9). If the Capabilities response contains default values in metadata items (such as WMS, Service or ArcIMS) the user is informed by warning message. The service is available at http://gis.vsb.cz/ogctest/.

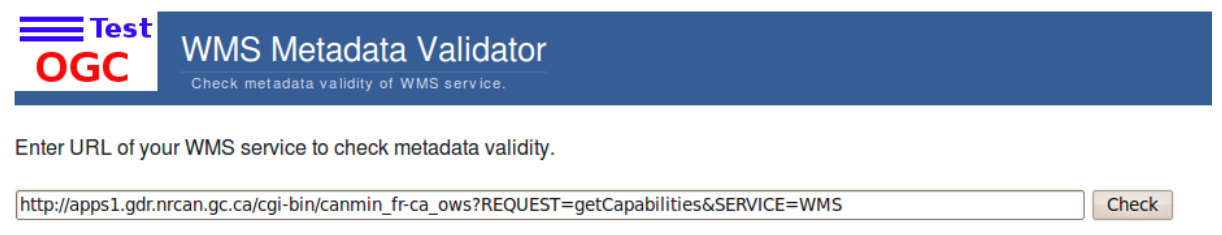

Figure 8: WMS Metadata Validator service

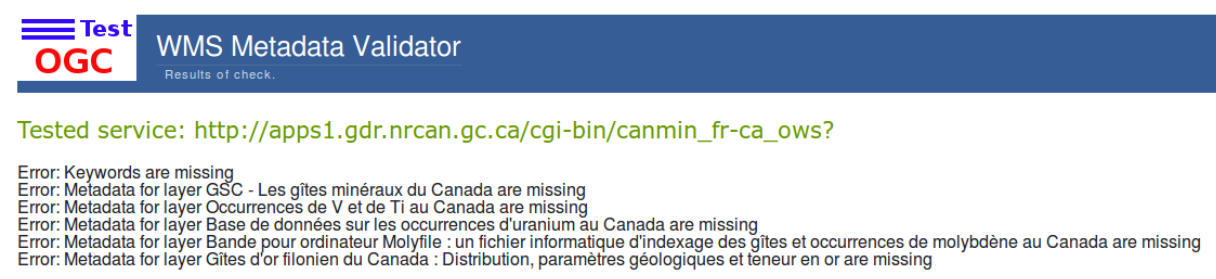

Figure 9: Results of validation

\section{How to use geodata without metadata in a correct way}

Intelligent map systems are living systems with knowledge base that can grow with every usage. In a case when there is a back correction from an expert then the system can learn which situation leaded to the wrong geodata usage. Shared information about geodata usage can help with fill in at least one metadata item, that can be generally named history of geodata usage. In many cases this metadata item is more important than the other. So we can probably in a long term usage use geodata without metadata in a correct way, but there must be intelligent map systems available for public usage and experts for cartography to evaluate created maps.

\section{Support}

The article is supported by Czech Science Foundation as a part of the project GA205/09/1159

- The Intelligent System for Interactive Support of Thematic Map Design

\section{References}

1. WMS OGC - Web Map Service - OGC http://www.opengeospatial.org/standards/wms

2. Růžička J. Pomohou webové služby odstranit noční můru kartografư? In. Sborník z konference 16. kartografická konference (Mapa v informační společnosti). Brno. 2005. 
Univerzita Obrany. 10s. ISBN 80-7231-015-1. Dostupné na WWW:

http://gisak.vsb.cz/wsco/publikace/Ruzicka_2005_Brno.pdf

3. Růžička J.; Kaszper, R. Opět o metadatech v geoinformatice. In. Sborník z konference 1. národní kongres v Česku Geoinformatika pro každého. Mikulov 29. - 31. května 2007. 8 s. Dostupné na WWW:

http://gis.vsb.cz/ruzicka/pub/2007/RuzickaKaszperFormatovane.pdf 